\title{
INVESTIGATION OF THE RELATIONSHIP BETWEEN ECONOMIC COMPLEXITY LEVEL AND HUMAN DEVELOPMENT LEVEL: COMPARISON OF DEVELOPED AND DEVELOPING COUNTRIES
}

\author{
DOI: 10.17261/Pressacademia.2019.1129 \\ JMML-V.6-ISS.3-2019(4)-p.162-174

\section{Semanur Soyyigit ${ }^{1}$, Ercan Eren ${ }^{2}$, Elife Akis ${ }^{3}$} \\ ${ }^{1}$ Erzincan Binali Yildirim University, Department of Economics, Yalnizbag Campus, Erzincan, Turkey, \\ semanur.soyyigit@erzincan.edu.tr, ORCID: 0000-0002-5679-6875 \\ ${ }^{2}$ Yildiz Technical University, Department of Economics, Davutpasa Campus, Istanbul, Turkey, \\ eren@yildiz.edu.tr, ORCID: 0000-0003-4513-278X \\ ${ }^{3}$ Istanbul University, Department of Economics, Beyazit Campus, Istanbul, Turkey, \\ elifakis@istanbul.edu.tr, ORCID: 0000-0002-5443-4045
}

Date Received: June 25, 2019

Date Accepted: September 23, 2019

To cite this document

Soyyigit, S., Eren, E., Akis, E., (2019). Investigation of the relationship between economic complexity level and human development level: comparison of developed and developing countries. Journal of Management, Marketing and Logistics (JMML), V.6(3), p.162-174.

Permemant link to this document: http://doi.org/10.17261/Pressacademia.2019.1129

Copyright: Published by PressAcademia and limited licenced re-use rights only.

\begin{abstract}
Purpose- The purpose of this study is to examine whether there is a difference between developed and developing countries in terms of the relationship between economic complexity level and human development level. Examining whether there is a long-term relationship between these two variables constitutes the main motivation of the study.

Methodology- In the present study, Bai and Carrion-I-Silvestre cointegration test has been applied to the data for G20 countries within the period from 1992 to 2017.

Findings- For all countries except the US, HDI has an impact on the ECI. The impact of HDI on ECI is negative in Germany, France, United Kingdom, Italy and Japan while it is positive in other countries. According to these results; in developed countries except Canada and Australia, human development has a negative impact on economic complexity level.

Conclusion- Results mean that improvements in indicators such as education, health, etc. in developing G20 countries develop human development level, and this development increases the sophistication of the economy; the quality of the products produced and exported by countries is developing to reflect the ability to use more complex knowledge together.
\end{abstract}

Keywords: Economic complexity level, human development level, panel data analysiss, panel cointegration analysis JEL Codes: O15, C23, L16

\section{INTRODUCTION}

Considering the basis of the growth and development theories in the economic literature, it is seen that the growth theories have been developed to find solutions to the problems of the developed countries and development theories have been developed to find solutions to the problems of the developing countries. In this context, it is seen that development theories have been developed since the 1950s after the Second World War. In fact, these theories have emerged from the recommendations given to the poor countries, which have recently gained their independence, on how to develop the natural resources which are the only assets that these countries have. The content of these recommendations is how to ensure the structural transformation in the economy over time and how to take the right steps in areas such as agriculture, industry, foreign trade (Berber, 2011). These studies were based on market efficiency idea which is at the core of neo-classical thought in order to induce the structural 
transformation in which manufacturing sector has a central role to enhance economic development. Additional contributions to the literature came from the Economic Commission for Latin America and the Caribbean (ECLAC). In this context, the study of R. Prebisch and C. Furtado focused on the two-pole world faced by developing countries. According to this; there were a global economic structure with two distinct poles, namely 'centre' and 'periphery' and differences existed between these two poles in terms of productive structure. In the studies, the problems arising from this dual structure such as international trade, technological differences, balance of payments and the state intervention were discussed (Gala et al, 2018).

Gala et al (2018) stated that productive sectors differ in terms of their growth and development potential and manufacturing industry sectors have the dynamics that would activate the development process in terms of increasing returns, high technological change, innovation and the division of labour. According to this; the agriculture and mining sectors do not allow such a technological change. On the other hand, the empirical testing of the arguments of these economists has been made possible with the development of economic complexity approach by Hausmann and Hidalgo.

In this study, by relying on the ideas that the sophistication levels of the products produced and exported by the countries determines the level of economic complexity of these countries and that economic complexity used commonly to explain structural transformation, it is aimed to test whether the 'economic complexity' concept also explain human development of the countries. For this purpose, the relationship between economic complexity and human development levels is examined for the G20 community, which is a community that contains the world's 19 largest economies and which is composed of both developed and developing countries. Within this context, economic complexity concept and, the relationship between this concept and human development level are explained in Section 2. Literature review is presented in Section 3 and economic review of G20 countries is given in Section 4. In Section 5, methodological explanation and introduction of the data are given. Finally, findings of the study are presented in Section 6.

\section{THE RELATIONSHIP BETWEEN ECONOMIC COMPLEXITY AND HUMAN DEVELOPMENT LEVELS}

The concept of economic complexity has begun to be used frequently in the literature after being revealed with the study 'The Atlas of Economic Complexity' by Hausmann et al (2011). Hausmann et al (2011), with reference to the idea of A. Smith that the division of the labour is the secret of the wealth of the nations, made more modern interpretation of this idea saying that division of labour gives opportunity to access to the knowledge that is not possible to reach individually. Because the knowledge in a society is not merely the sum of the information that individuals in this society have. The diversification of the knowledge among individuals and the ability to use existing knowledge by collating via complex interaction networks makes this knowledge more effective. The authors who distinguish explicit knowledge from tacit knowledge call the aggregate of this tacit knowledge 'capabilities'. Within this context, complexity level of an economy is related to diversification of useful knowledge it contains. In other words, while economic complexity level of an economy is determined by how effectively existing knowledge is combined, the result obtained reflects on the composition of production (Hausmann et al, 2011).

Hausmann et al. (2011) who developed an index measures the level of economic complexity, have made use of international trade data. The conclusion of this method is the existence of a relation between sophistication level of the products which the country exports and the complexity level of this economy. Hence, countries can increase their levels of economic complexity by increasing their competitiveness in industries involving complex / sophisticated products.

Hidalgo (2009) states that what a country produces and exports becomes more substantial rather than how much it produces and exports. In other words, it is a situation in which the quality of production and export becomes more important than its volume. Because the degree of sophistication of each product is not same and, what will determine the long-term income levels of countries will be the sophistication level rather than the size of the trade volumes (Hidalgo, 2009).

Hidalgo and Hausmann (2009) identified the relationships between the economic complexity index and various macroeconomic indicators as a result of their empirical study. From this point of view, they made inferences about the importance of the level of economic complexity. Accordingly, economic complexity index; (i) gives information about the existing set of knowledge and capabilities of a country, (ii) has a strong correlation with per capita income level, (ii) enables to estimate future growth, (iv) is determinant on the complexity level of export structure for future.

In fact, all these studies link the country's production structure with the economic development model. This relationship emphasizes the role of a transformation from a natural-based and agricultural production structure to a more sophisticated structure (Lapatinas, 2016). This is in fact the structural transformation which is defined as the increase of share of industry sector in some indicators such as total output, employment and export accompanied by a decrease of share of agricultural sector (Berber, 2011). 
So, what is the relationship between the level of economic complexity that expresses the structural transformation of countries and the level of human development? Before answering this question, it is useful to stand on the concept of human development.

The concept of human development and its measurement, the Human Development Index (HDI), was first used in 1990 in the Human Development Report published by the United Nations. The concept of human development has two dimensions: first, the formation of human abilities such as health, knowledge and skills; the second is the benefits that people get from these abilities (being active in cultural, social and political affairs etc.). The main motivation for this concept came from the fact that there is no direct link between income growth and human development. Here, it is stated that income is not just a result but also a tool. It is stated that income can be spent on medicines as well as on narcotic and therefore it is more important how to use rather than income level. In addition, the examples such as the countries with low income levels and high levels of human development, and the countries with high income levels and low levels of human development, have also revealed this distinction. In this sense, human development refers to the process of developing people's choices and the level of welfare they achieve (UNDP, 1990).

There are opinions about that both positive and negative interactions exist between economic complexity and human development level (UNDP, 1990). According to this; level of economic complexity has a positive impact on people by increasing access to facilities such as better education and better health care etc., by enabling them to achieve a better standard of living. As well as this direct impact, it is also stated that level of economic complexity can have some positive impacts indirectly. According to this; economic complexity can make people open to new products; can offer more options and lifestyle. Thus, it can support human development. However, some negative effects are likely to occur. Ecological unsustainability caused by consumption, production and resource use of increasing demand can be expressed as one of these negative effects. In addition, the uncertainty of decision processes due to increasing complexity can lead to a dissatisfaction in individuals (UNDP, 1990). On the other hand, it is also possible for human development level to have an impact on the economic complexity level. When there is a progress in the indicators affecting human development level such as education, health etc. there may be an increase in the ability of the economy to combine existing knowledge and to produce more sophisticated products.

\section{LITERATURE REVIEW}

The economic complexity index is a measure that has recently started to take part in empirical studies in the field of economics. For this reason, the number of studies dealing with the direct relationship between economic complexity and human development level is quite low. On the other hand, studies examining the relationship between economic complexity and per capita income and income distribution are available in the literature. In one of these studies, Hartmann et al (2017) analyzed the relationship among economic complexity, institutional structure and income inequality by using indicators such as economic complexity index, international trade, Gini coefficient, per capita income, average schooling rate, population, political stability and government effectiveness. The results of the analysis showed that there is a negative relationship between high economic complexity and income inequality (Hartmann et al., 2017).

In another study, Stojkoski and Kocarev (2017) examined the relationship between economic complexity and growth in Southeast and Central European countries. Their findings revealed that the level of economic complexity is an explanatory variable over long-term growth; however, they have found that productive information, which is the basis of economic complexity, is not explanatory on the change in income levels of countries in the short term (Stojkoski and Kocarev, 2017).

Hartmann's study (2014) which is one of the studies on the interaction between the level of economic complexity and the level of human development, analyses the effect of economic diversity on the level of human development and per capita income via simple regression models and covers 121 countries and 772 sectors. In the analysis using the export data of 1, 2 and 4 digit items based on the SITC Rev.4 classification, the Entropy Index (EI), Herfindahl-Hirschman Index (HHI) and Revealed Comparative Index (RCA) were used to measure export diversification. In the regression models where these indices were used as independent variables, the human development index and the per capita income were used as dependent variables. The results of the analysis indicated that all indices representing the export diversity were effective on dependent variables regardless of which index or how many digit export data were used. On the other hand, economic diversity is more effective on human development than on per capita income (Hartmann, 2014).

Lapatinas (2016) analysed the relationship between the economic complexity and human development index variables by using regression analysis for 126 countries. As a result of the analysis, it was concluded that economic sophistication and export diversity, which are the driving force of economic development, have no effect on human development.

Ferraz et al. (2018) tested how effective the Latin American and Asian countries can be in transforming economic complexity into human development. As a result of the analysis using data envelopment analysis, all Asian countries except China and the 
Philippines were found to be effective in this transformation in 2014. They also showed that Cuba has a good criterion in terms of efficiency. In addition, Japan, South Korea and Singapore have become more effective over time. The result of this study is that, in contrast to the findings of Lapatinas (2016) the more sophisticated countries are more effective in creating human development.

Gala et al (2018), using the annual data for 147 countries in the period of 1979-2011, tested whether the complexity of the export structures of the countries explained the convergence or divergence between rich and poor countries. Their findings show that countries with high export sophistication are stronger in closing the income gap with developed countries than countries with low export sophistication. Therefore, the higher the economic complexity of the export products of the developing countries, the higher the convergence of the revenues of these countries to the developed country level.

\section{ECONOMIC OUTLOOK IN G-20 COMMUNITY}

Before presenting the results of the analysis, examination of the G-20 countries included in the analysis in terms of some indicators will provide an idea in terms of evaluating the findings of the analysis. For this purpose, Graph 1 presents the per capita income levels of the countries in question in comparison with each other and the world average.

\section{Figure 1: GDP per capita (PPP, US \$, 2011)}

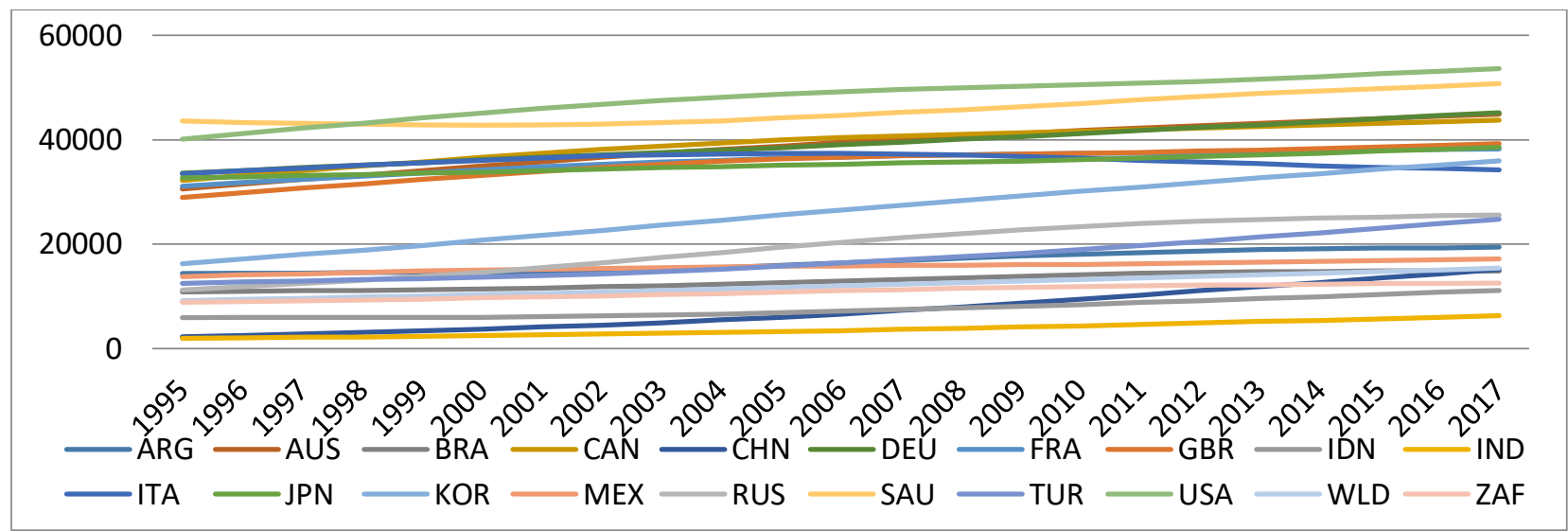

Note: The trends of the series were obtained by using the Hodrick - Prescott method.

Source: Organized by using World Bank statistics.

Figure 1 shows the per capita income of G-20 countries. Accordingly, the country with the highest per capita income is the United States; followed by Saudi Arabia, Germany, Australia and Canada. Following these 5 countries are the United Kingdom, France, Japan and Italy. Among the countries that are in the top 9 in terms of income per capita, all countries except Saudi Arabia are in the developed country class. As it is known, Saudi Arabia is a developing country with high per capita income due to high oil export revenues. Among the other developing countries, South Korea shows a distinct difference. South Korea is followed by Russia, Turkey and Argentina. South Africa, China, India and Indonesia stay below the world average per capita income. 
Figure 2: Economic Complexity Level in G-20 Countries

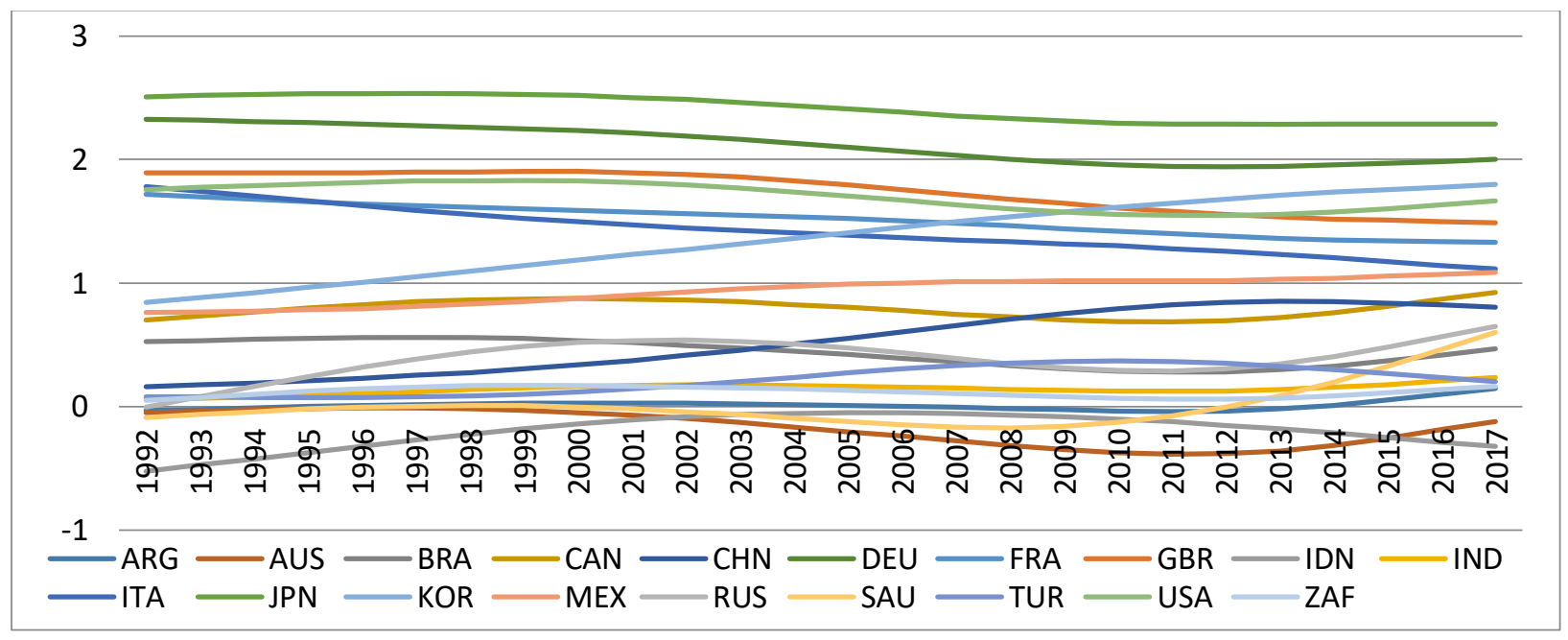

Note: The trends of the series were obtained by using the Hodrick - Prescott method.

Source: Organized by using MIT - OEC statistics.

When the countries are evaluated in terms of economic complexity, Japan ranks first; followed by Germany, United Kingdom, USA, France and Italy. It is observed that the level of economic complexity of South Korea has reached the level of developed countries since 2005. The economic complexity levels of Australia and Canada are at the level of developing countries.

\section{Figure 3: Human Development Level in G-20 Countries}

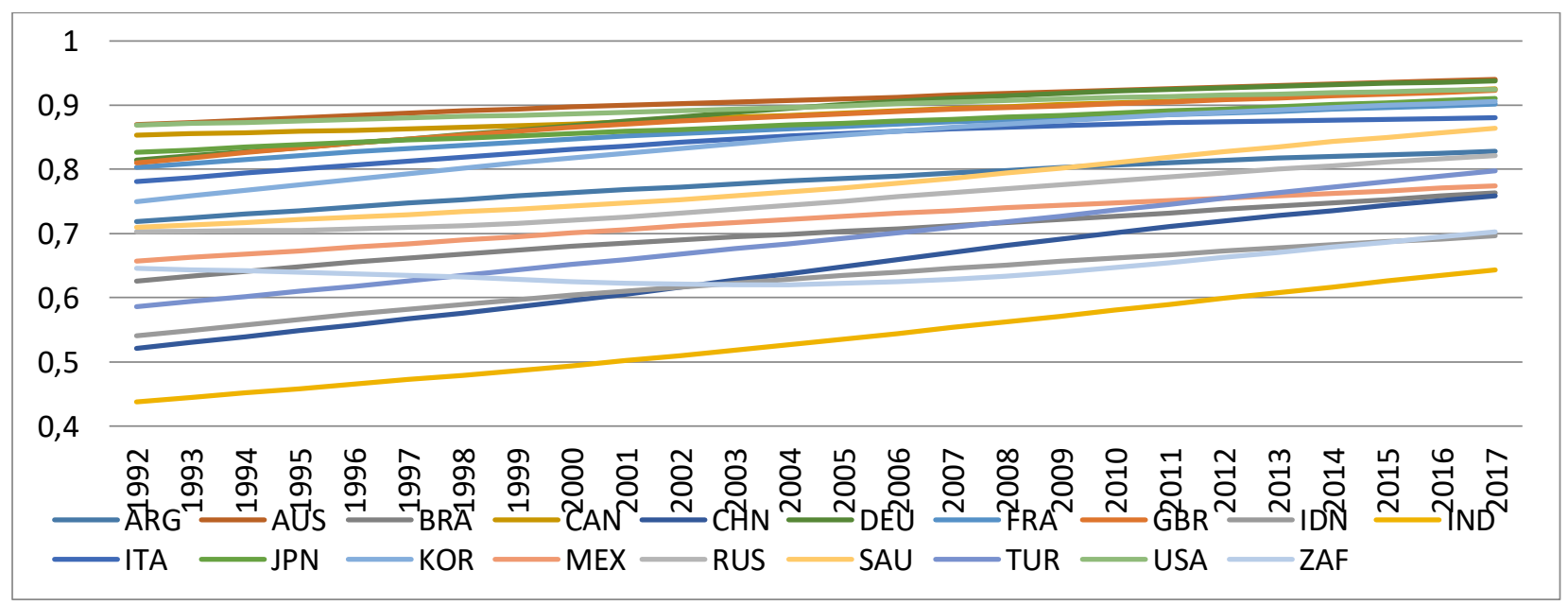

Note: The trends of the series were obtained by using the Hodrick - Prescott method.

Source: Organized by using United Nations statistics.

As can be seen in Figure 3, where there is a comparison of countries according to human development indices, there is a clear distinction between developed and developing countries; developed countries constitute a cluster at the top of the chart and developing countries are located as a separate cluster under the developed countries. The only exception here is South Korea. In the list of human development index, South Korea is located in the cluster of developed countries. 
Figure 4: Average ECl and HDI values of Developing and Developed Countries (1992-2017)

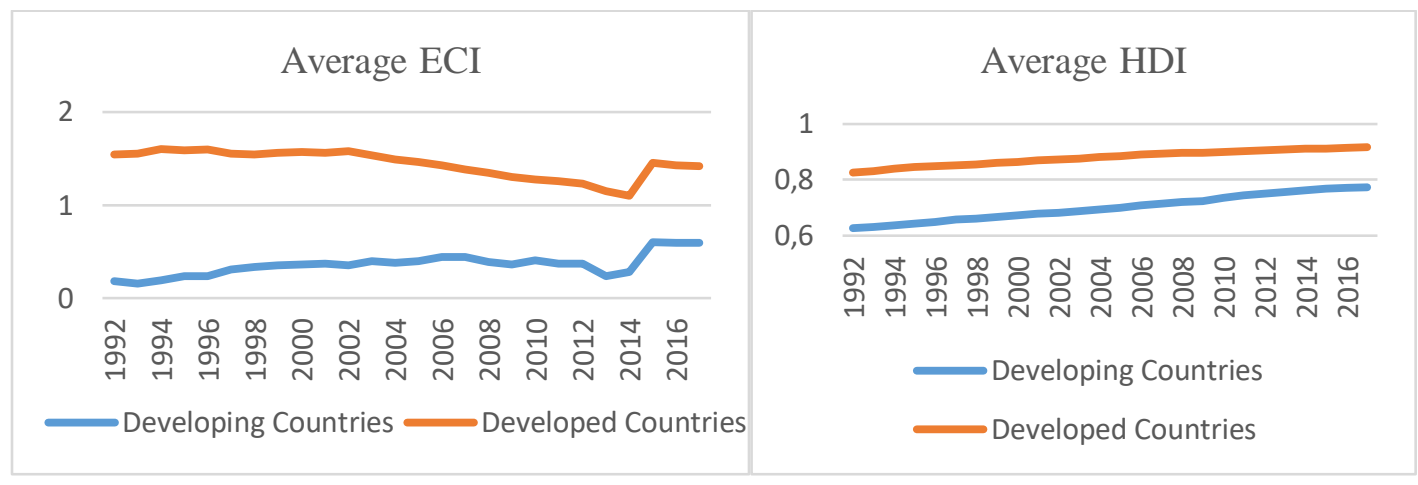

When the average $\mathrm{ECl}$ and $\mathrm{HDI}$ values are drawn within the framework of developing and developed countries, as can be seen in Graph 4, while the economic complexity levels of developed countries are decreasing in average over time, it is seen that there is an average increase for developing countries. In this sense, it can be said that the difference between the economic complexity levels of developed and developing countries of G-20 community tends to decrease in time. When evaluated in terms of human development levels, there is an average increase in this index in terms of both developed and developing countries; however, it can be stated that the gap between the developed and developing countries is in a decreasing trend since the increase in developing countries is higher.

\section{Figure 5: ECI-HDI Distributions of Developing and Developed Countries}
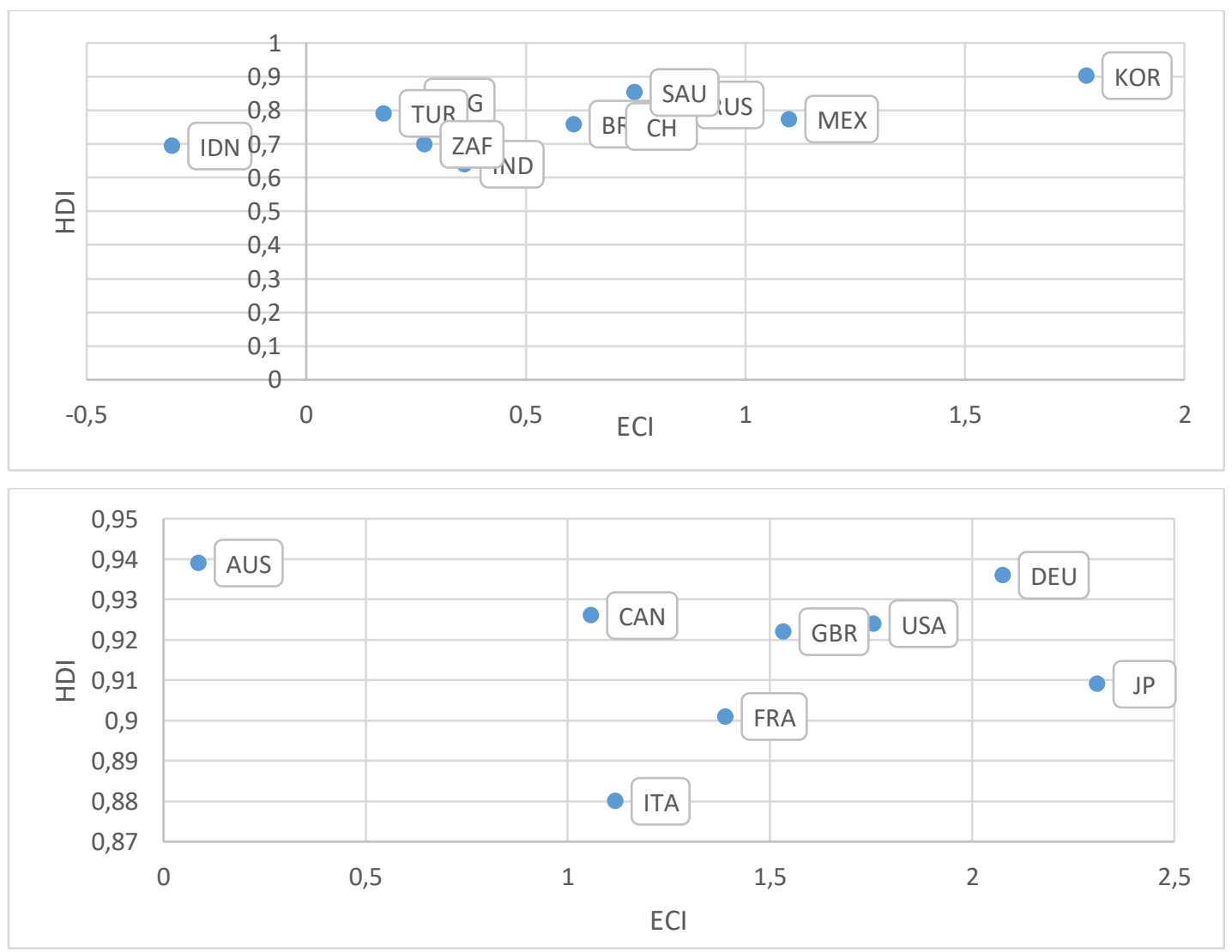
As seen in Graph 5, Korea, which is located in the developing country group, shows a marked difference from the other countries in this group. Korea has higher value both in $\mathrm{ECl}$ and $\mathrm{HDI}$. In this group, Indonesia is another country that exhibits markedly difference from other countries in the group. The $\mathrm{ECl}$ value of Indonesia is on the negative axis and the HDI value is relatively low. When we look at the developing countries, it is observed that Australia is different from the developed countries in G-20. Although Australia's $\mathrm{ECl}$ value is quite low, the country has the highest HDI value among developed countries.

\section{DATA AND ECONOMETRIC METHODOLOGY}

As mentioned at the beginning of the study, the hypothesis of this study is to find out whether there is a relationship between the level of economic complexity and the level of human development in the G-20 community. For this purpose, panel cointegration analysis is applied to the HDI, which measures the level of human development, and the ECl, which measures the level of economic sophistication.

Table 1: Variables and the data sources

\begin{tabular}{lll}
\hline Variable Name & Explanation of the variable & Data source \\
\hline ECI & Economic complexity index & $\underline{\text { http://hdr.undp.org/en/data\# }}$ \\
& MIT - Obsevatory of Economic Complexity \\
HDI & Human development index & $\underline{\text { https://atlas.media.mit.edu/en/rankings/country/eci/ }}$
\end{tabular}

G-20 community consists of 19 countries (Argentina, Australia, Brazil, Canada, China, Germany, France, United Kingdom, Indonesia, India, Italy, Japan, Korea, Mexico, Russia, Saudi Arabia, Turkey, the United States ve South Africa) and European Union Commision. According to the classification of the United Nations; Australia, Canada, Germany, France, Italy, United Kingdom, Japan and the US are developed countries while the other countries are considered as developing countries (UN, 2019). The analysis period was limited to the period of 1992-2017 due to the constraint of the data of Russia. Before the explanation of the findings, information is given about the theoretical method used.

Panel cointegration analysis is a method used to analyze the long-term relationship between series of panels as in time series analysis (Şak, 2015). The cointegration analysis is based on the idea that if the order of integration of the non-stationary series is the same, then the linear compositions of these series may be stationary and that there may be a long-term relationship between the series. Based on this idea, panel cointegration tests are used in the panel data analysis in order to test whether there is a longterm relationship between the variables despite the permanent shocks affecting the system (Yerdelen Tatoğlu, 2013).

Therefore, in order for cointegration tests to be applied to the panel data, firstly, the series must have unit roots at the level and become stable at the same level. The unit root tests used in the panel data analysis vary according to whether there is a crosssectional dependence in the series. Therefore, it is necessary to test the cross-sectional dependence of the series first. Various tests have been developed to examine the cross-sectional dependence of the series in panel data analysis. The first one is the Lagrange Multiplier (LM) test developed by Breusch and Pagan. The test statistic of the LM test (CDLM1) used when the time dimension of the panel is greater than the cross-sectional dimension ( $T>N$ ) is as follows (Pesaran, 2004):

$C D L M_{1}=T \sum_{i=1}^{N-1} \sum_{j=i+1}^{N} \hat{\rho}_{i j}^{2}$

$\hat{\rho}_{i j}^{2}$ in Equation (1) refers to the estimation of pairwise correlation of the residuals. Breusch and Pagan showed that CDLM1 test statistic was distributed asymptotically $\chi^{2}$ under the null hypothesis that there is no cross-sectional dependence. Pesaran has developed a new test that can be used in cases where $N$ and T have large values. The test statistic for this test (CDLM2) is the scaled version of CDLM1 (Pesaran, 2004): 


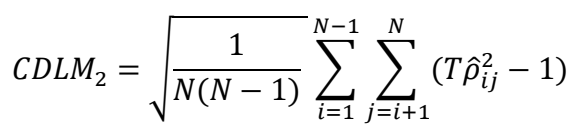

Pesaran et al. then developed a test with a different version of the LM test. The bias-corrected LM statistic of this test (LMadj) is as follow (Pan et al., 2015):

$L M_{a d j}=\sqrt{\left(\frac{2 T}{N(N-1)}\right)} \sum_{i=1}^{N-1} \sum_{j=i+1}^{N} \hat{\rho}_{i j} \frac{(T-k) \hat{\rho}_{i j}^{2}-\mu_{T i j}}{\sqrt{v_{T i j}^{2}}}$

$\mu_{T i j}$ and $v_{T i j}^{2}$ in Equation (3) refers to the average and the variance of $(T-k) \hat{\rho}_{i j}^{2}$, respectively.

In econometric analysis, when working with non-stationary series, spurious regression problem is encountered. Therefore, it is necessary to ensure that the series are stationary before the analysis. The unit root tests used in the determination of the stationarity in the panel data analysis are separated as the first generation tests and the second generation tests. First generation tests are used in the assumption that there is no cross-sectional dependence in the series, while second generation tests are used in case of the existence of cross-sectional dependence (Yerdelen Tatoğlu, 2013).

As can be seen in the findings section in detail, the cross-section dependence was determined in both $\mathrm{HDI}$ and $\mathrm{ECl}$ series used in this study. For this reason, Cross-Sectionally Augmented Dickey-Fuller (CADF) test, which is a second-generation test, was used to determine the stationarity of the series. This test can be used both when the cross-sectional dimension is greater than the time dimension ( $\mathrm{N}>\mathrm{T}$ ) and when the time dimension is greater than the cross-sectional dimension (T> N). In addition, Monte Carlo simulations have shown that even for small $\mathrm{N}$ and T values, strong results are obtained (Pesaran, 2007).

The following model is used based on the assumptions that $y_{i t}$ is an observation belongs to cross-section $\mathrm{i}$ and to time $\mathrm{t}$ and that it is built depending on the simple dynamic linear heterogeneous panel data model (Pesaran, 2007):

$y_{i t}=\left(1-\emptyset_{i}\right) \mu_{i}+\emptyset_{i} y_{i, t-1}+u_{i t}, \quad i=1, \ldots, N ; \quad t=1, \ldots ., T$

The initial value $y_{i 0}$ has a density function with finite means and variances, and the error term $u_{i t}$ has a single-factor structure.

$u_{i t}=\gamma_{i} f_{t}+\varepsilon_{i t}$

In Equation (5), $f_{t}$ refers to unobserved common effect and $\varepsilon_{i t}$ refers to the unit-specific error term. Then, Equation (4) and Equation (5) can be written as follow:

$\Delta y_{i t}=\alpha_{i}+\beta_{i} y_{i, t-1}+\gamma_{i} f_{t}+\varepsilon_{i t}$

Based on $\alpha_{i}=\left(1-\emptyset_{i}\right) \mu_{i}, \beta_{i}=-\left(1-\emptyset_{i}\right)$ and $\Delta y_{i t}=y_{i t}-y_{i, t-1}$; hypothesis of the unit root test is stated as follows:

$H_{0}: \beta_{i}=0$ (unit root for all $i^{\prime} s$ )

$H_{1}: \beta_{i}<0$ (stationary)

CADF test gives test statistics for both cross-sections and overall panel. Test statistics for the overall panel (CIPS) are calculated by taking the average of test statistics for cross-sections (Pesaran, 2007):

CIPS $=N^{-1} \sum_{i=1}^{N} t_{i}(N, T)$

In Equation (7), $t_{i}(N, T)$ refers to the CADF test statistic that belongs to cross-section i (Pesaran, 2007).

As is seen in the findings section, CADF test results show that HDI and ECI have unit root at level and both variables become stationary at first-difference. If economic variables contain unit roots, the linear combination of these series may be stationary and there may also be a long-term relationship between the variables. Despite the persistent shocks affecting the system, the existence of long-term relationship between variables can be examined by panel cointegration tests (Yerdelen Tatoğlu, 2013). 
Panel cointegration tests are separated into two according to whether there is cross-sectional dependence in the residuals of the long-term equation between variables. If there is no cross-sectional dependence of the long-term equation between variables, the first-generation cointegration tests and second-generation cointegration tests, if any, are applied. In this study, Bai and Carrion-i-Silvestre test which is a second-generation panel cointegration test, was applied due to the existence of cross-sectional dependence of long-term equation.

Bai and Carrion-i-Silvestre, who used a common factor model to define common shocks and common stochastic trends, acted from the model in Equation (8) (Bai and Carrion-I-Silvestre, 2013):

$Y_{i, t}=\mu_{i}+\gamma_{i} t+X^{\prime}{ }_{i, t} \beta_{i}+F^{\prime}{ }_{t} \lambda_{i}+e_{i, t}, \quad i=1,2, \ldots ., N ; \quad t=1,2, \ldots \ldots, T$

In Equation (8), $\mu_{i}+\gamma_{i} t$ refers to deterministic component, $X_{i, t}$ refers to vector of observeble I(1) variables, $F_{t}$ refers to the unobservable common shock vector whose effect differs by cross-section units via $\lambda_{i}$ and, $e_{i, t}$ refers to the error term vector specific to cross-section units. When integration order of $F_{t}$ is $\mathrm{I}(1)$, this term refers to unobservable cross-section common stochastic trend in this cointegration test. If $e_{i, t}$ is stationary at level, then it is said that $Y_{i, t}, X_{i, t}$ and $F_{t}$ are cointegrated, even if $Y_{i, t}$ and $X_{i, t}$ are not cointegrated. That is to say, cointegration between $Y_{i, t}$ ve $X_{i, t}$ is allowed even a small number of unobservable common stochastic trend. $Y_{i, t}$ and $X_{i, t}$ becomes cointegrated, when both $e_{i, t}$ and $F_{t}$ are stationary at level. In this situation, $F_{t}$ is accepted as common shock that capture the cross-section dependence. In sum, it is aimed in this test not only to control of crossection dependence, but also to determine whether $F_{t}$ which is unobservable component, is stationary.

Bai and Carrion-i-Silvestre (Bai and Carrion-I-Silvestre, 2013) used the square of the MSB (Modified Sargan - Bhargava) statistics to test the $\mathrm{H}_{0}$ hypothesis representing that there was no cointegration. The MSB statistics have some optimal features among invariant tests against heterogeneous trends. When calculating panel cointegration test statistics, individual statistics that are calculated for each cross-section unit in different methods, are used. Bai - Carrion-i-Silvestre test offers three separate test statistics (Bai and Carrion-I-Silvestre, 2013): MSB, P and $\mathrm{P}_{\mathrm{m}}$. The first of the methods used to obtain panel test statistic by combining individual statistics, standardizes the average of these individual statistics. Accordingly, MSB statistic is as follows:

$M S B_{\xi}=\sqrt{N} \frac{\overline{M S B_{\xi}(l)}-\bar{\vartheta}}{\bar{\zeta}} \sim N(0,1)$

The terms in Equation (9) can be written as follows:

$\overline{M S B_{\xi}(l)}=N^{-1} \sum_{i=1}^{N} M S B_{\xi}(i)$

$\bar{\vartheta}=N^{-1} \sum_{i=1}^{N} \vartheta_{i}$

$\zeta^{2}=N^{-1} \sum_{i=1}^{N} \zeta_{i}^{2}$

In equations above, $\vartheta_{i}$ ve $\zeta_{i}$ correspond to mean and variance of $\operatorname{MSB}_{\xi}(i)^{\prime}$ s, respectively.

The second method is to define panel statistics through the combination of individual p-values. Here, under the assumption that individual error terms $\xi_{i, t}$ do not have cross-section dependency, Fisher type test statistics are obtained as follows:

$P=-2 \sum_{i=1}^{N} \ln p_{i} \sim \chi_{2 N}^{2}$

In Equation (13), $p_{i}$ refers to $\mathrm{p}$-values belong to $M S B_{\xi}(i)$ for each cross-section. Another method is a calculation method of test statistics suggested by Choi, when $N \rightarrow \infty$. Accordingly, $\mathrm{P}_{\mathrm{m}}$ test statistic is as follows:

$P_{m}=\frac{-2 \sum_{i=1}^{N} \ln p_{i}-2 N}{\sqrt{4 N}} \sim N(0,1)$

If a long-term relationship is found between the variables as a result of the cointegration test, this long-term relationship can be estimated. Delta test is used before the cointegration coefficients are estimated to determine whether the slope coefficients are homogeneous or heterogeneous. Since the countries analyzed in the study covered both developed and developing countries and 
these countries have different characteristics in economic and socio-cultural terms, long-term coefficient estimation was made by means of the Augmented Mean Group (AMG) method. The AMG method developed by Eberhardt and Bond (Eberhardt and Bond, 2009) is an estimation method that takes into account the cross-sectional dependence. It can also calculate the cointegration coefficients of the panel and the countries that make up the panel (Eberhardt and Bond, 2009).

\section{FINDINGS}

In this part of the study, findings of the tests explained methodological above are presented. Accordingly, results of the crosssectional dependence test belonging to both the variables and the models are presented in Table 2.

Table 2: Results of Cross-Sectional Dependence Test

\begin{tabular}{|c|c|c|c|c|c|c|c|c|}
\hline & $\mathrm{ECl}$ & & HDI & & $\begin{array}{r}\text { Mode } \\
\text { (Dependent var }\end{array}$ & able: ECI) & $\begin{array}{r}\text { Mode } \\
\text { (Dependent } \\
\text { HDI) }\end{array}$ & riable: \\
\hline & Test statistics & p value & Test statistics & $p$ value & Test statistics & $p$ value & Test statistics & $p$ value \\
\hline CDLM1 & 1475.065 & 0.000 & 3930.3 & 0.000 & 1625 & 0.000 & 1669 & 0.000 \\
\hline CDLM2 & 69.48834 & 0.000 & 202.2523 & 0.000 & 12.02 & 0.000 & 227.8 & 0.000 \\
\hline LMadj & 69.10834 & 0.000 & 201.8723 & 0.000 & 217.8 & 0.000 & 34.5 & 0.000 \\
\hline
\end{tabular}

According to the results of the cross-sectional dependence test in Table 2, since the probability value is less than 0.05 , the null hypothesis that there is no cross-sectional dependence is rejected. In other words, there is a cross-sectional dependence in variables and models. The results of the CADF test that is one of the second generation unit root tests which takes into account the cross-sectional dependence, are presented in Table 3.

Table 3: CADF Unit-Root Test Results

\begin{tabular}{lcccc}
\hline Variables & \multicolumn{2}{c}{ CIPS statistics - Level } & \multicolumn{2}{c}{ CIPS Statistics - First difference } \\
& Constant & Constant and trend & Constant & Constant and trend \\
\hline $\mathrm{ECl}$ & -1.59 & -2.462 & -2.669 & -2.901 \\
$\mathrm{HDI}$ & -2.24 & -2.507 & -2.535 & -2.743 \\
\hline
\end{tabular}

Critical values for $0.01,0.05$ ve 0.10 significance levels are $-2.38,-2.20$ ve -2.11 in constant model and $-2.88,-2.72$ ve -2.63 in constant-trend model.

According to these results, $\mathrm{ECl}$ variable has unit-root in both the constant and constant-trend model, and it becomes stationary at first difference. When it comes to HDI variable, it is stationary at level in constant model with 0.05 significance level and it has unit root at level in constant-trend model. HDI becomes stationary at first difference. Hence, it is seen that both of the variables becomes stationary at first-difference meaning that integration level of both are I(1). This result suggests that there may be a long-term relationship between these variables. In this study, Bai and Carrion-i-Silvestre cointegration test which is a secondgeneration test has been applied to the variables. The reason why second-generation cointegration test is chosen is the detection of cross-sectional dependence in residuals of the models (Table 2).

Table 4: Cointegration Test Results

\begin{tabular}{|c|c|c|c|c|c|c|c|c|}
\hline & \multicolumn{4}{|c|}{ Dependent variable : ECI } & \multicolumn{4}{|c|}{ Dependent variable: HDI } \\
\hline & \multicolumn{2}{|c|}{ Constant model } & \multicolumn{2}{|c|}{ Constant-trend model } & \multicolumn{2}{|c|}{ Constant model } & \multicolumn{2}{|c|}{ Constant-trend model } \\
\hline & $\begin{array}{c}\text { Test } \\
\text { statistics }\end{array}$ & p-value & $\begin{array}{c}\text { Test } \\
\text { statistics }\end{array}$ & p-value & $\begin{array}{c}\text { Test } \\
\text { statistics }\end{array}$ & p-value & $\begin{array}{c}\text { Test } \\
\text { statistics }\end{array}$ & p-value \\
\hline MSB & $-1,436$ & 0,076 & 41,296 & 1,000 & $-1,535$ & 0,062 & 3,713 & 1,000 \\
\hline$P$ & 2,156 & 0,016 & 7,744 & 0,000 & 1,249 & 0,106 & $-1,343$ & 0,910 \\
\hline $\mathrm{P}_{\mathrm{m}}$ & 56,8 & 0,025 & 105,508 & 0.000 & 48,887 & 0,111 & 26,292 & 0,924 \\
\hline
\end{tabular}

In the Bai and Carrion-i-Silvestre cointegration test, alternative hypothesis that representing the existence of cointegration is tested against the null hypothesis representing that there is no cointegration. The probability value of at least one of the MSB, $\mathrm{P}$ 
and $\mathrm{Pm}$ values should be less than 0.05 for the null hypothesis to be rejected. When the results in Table 4 are evaluated, there is no long-term relationship between variables in the model where HDI is dependent variable; however, in the model where the ECI is a dependent variable, it is found that there is a long-term relationship between the variables.

Table 5: Estimated Long Term Coefficient of the Panel

\begin{tabular}{lcc}
\hline Independent variable & Coefficient & p-value \\
\hline HDI & $1,191,478$ & 0,132 \\
\hline
\end{tabular}

After existence of cointegration between variables is revealed, long-term coefficient is estimated. Delta test is applied to determine whether the long-term coefficients are homogeneous or heterogeneous. However, since the countries analyzed in this study have very different economic, social and cultural characteristics, it is assumed that long-term coefficients are heterogeneous without applying Delta test. Table 5 presents the coefficient estimation results for the overall panel under the assumption that the long-term coefficients are heterogeneous. According to the results in Table 5, there is no significant relationship between HDI and $\mathrm{ECl}$ for the overall panel, assuming that long-term coefficients are heterogeneous. The long-term coefficient estimates for the cross-section units are presented in Table 6.

Table 6: Coefficient Estimates for Cross-Section Units (Dependent Variable: ECl)

\begin{tabular}{lcc}
\hline Countries & Coefficient & p-value \\
\hline Argentina & 36,227 & $0,000^{*}$ \\
Australia & 18,411 & $0,054^{* * *}$ \\
Brazil & 0,7188 & $0,096^{* * *}$ \\
Canada & 47,575 & $0,000^{*}$ \\
China & 22,384 & $0,000^{*}$ \\
Germany & $-21,503$ & $0,000^{*}$ \\
France & $-30,278$ & $0,000^{*}$ \\
United Kingdom & $-25,155$ & $0,000^{*}$ \\
Indonesia & 15,877 & $0,036^{* *}$ \\
India & 13,517 & $0,000^{*}$ \\
Italy & $-61,485$ & $0,000^{*}$ \\
Japan & $-29,867$ & $0,001^{*}$ \\
Korea & 56,649 & $0,000^{*}$ \\
Mexico & 37,993 & $0,000^{*}$ \\
Russia & 56,018 & $0,000^{*}$ \\
Saudi Arabia & 66,483 & $0,000^{*}$ \\
Turkey & 0,6381 & $0,095^{* * *}$ \\
United States & $-0,4818$ & 0,488 \\
South Africa & 14,779 & $0,023^{* *}$ \\
\hline
\end{tabular}

$*, * *$ and $* *$ correspond to $0.01,0.05$ ve 0.10 significance levels, respectively.

According to the estimation results in Table 6; For all countries except the US, HDI has an impact on the ECl. This impact is at 0.10 significance level in Australia, Brazil and Turkey; at 0.05 significance level in South Africa; and for all other countries is at 0.01 significance level. The impact of $\mathrm{HDI}$ on $\mathrm{ECl}$ is negative in Germany, France, United Kingdom, Italy and Japan while it is positive in other countries. According to these results; in developed countries except Canada and Australia, human development has a negative impact on economic complexity level. The common characteristic of the countries where the level of human development positively affects the level of economic complexity is that they are developing countries (except Canada and Australia).

\section{CONCLUSION}

It is a known phenomenon that growth of GDP and of per capita income in one country to be a necessary but not sufficient factor for increasing the level of human development in that country. Developed countries, which have high income levels, have increased also their levels of human development. However, this situation is a more structural problem in developing countries. 
For this reason, in order to overcome this problem in developing countries, it is necessary to provide structural transformation which developed countries has overcome. Thus, it is aimed in this study to examine the interaction between human development index and the economic complexity index which represents the structural transformation and which have just started to be used in the literature.

In the literature, the positive and negative effects of economic complexity on human development are mentioned. However, the level of human development may also affect the level of economic complexity. It is also probable that education, health and income, which are the most basic indicators of human development index, affect the production and export sophistication, which expresses the level of complexity of the economy. For this purpose, the long-term relationship between these two variables has been tested for two models where both the level of economic complexity and the level of human development are considered to be dependent variables; long term relationship was determined in the model where the economic complexity index was dependent variable and the human development index was independent variable. This result shows that there is a long-term relationship between variables, despite persistent shocks affecting the system. Therefore, the level of human development has an impact on the level of economic complexity.

Although the analysis is based on the G-20 community, which consist of the largest 19 economies in the world, the member countries of this community exhibit very different characteristics in economic and socio-cultural terms. For this reason, pooled model was not used in the estimation of long-term coefficients in the analysis; long-term coefficients for each country were estimated separately. Long-term coefficients were found to be significant statistically for all countries in the community except the United States. Among these countries, the long-term coefficients of Germany, France, the United Kingdom, Italy and Japan have negative values. The common feature of these countries is that they are among the developed countries of the G20 community. This negative impact can be better understood if these result is considered in conjunction with Graph 4, and if it is remembered that the average $\mathrm{ECl}$ decreases accompanied by an increase in the average $\mathrm{HDI}$ in developed countries. Since the share of service sector in national income and export within developed countries increased and the economic complexity index was calculated by considering the products exported by the countries, it is seen that in developed countries $\mathrm{ECl}$ value is in the decreasing trend. On the other hand, the level of human development in these countries is increasing. Among the developed countries, Australia and Canada are the exceptions to this negative relationship.

When developing countries are considered, it is seen that human development level has positive effect on economic complexity level in all of these countries. This result means that improvements in indicators such as education, health, etc. develop human development, and this development increases the sophistication of the economy; the quality of the products produced and exported by countries is developing to reflect the ability to use more complex knowledge together.

\section{REFERENCES}

Bai, J., \& Carrion-i-Silvestre, J.L. (2013). Testing panel cointegration with unobservable dynamic common factors that are correlated with the regressors. Econometrics Journal, 16: 222-249.

Berber, M. (2011). iktisadi büyüme ve kalkınma. Trabzon: Derya Kitabevi.

Eberhardt, M., \& Bond, S. (2009). Cross-section dependence in nonstationary panel models: A novel estimator. MPRA, 17870.

Ferraz, D., Moralles, H.F. Campoli, J.S., Riberio de Oliviera, F.C., \& Aparecida do Nascimento Rebelatto, D. (2018). Economic complexity and human development: DEA performance measurement in Asia and Latin America. Gestão \& Produção, 25(4): 839-853.

Gala, P., Rocha, I.,\& Magacho, G. (2018). The structuralist revenge: Economic complexity as an important dimension to evaluate growth and development. Brazilian Journal of Political Economy , 38(2): 219-236.

Hartmann, D. (2014). Economic Complexity and Human Development. New York: Routledge.

Hartmann, D., Guevara, M.R., Jara-Figueroa, C., Aristaran, M., \& Hidalgo, C.A. (2017). Linking economic complexity, instutions and income inequality. World Development, 93: 75-93.

Hausmann, R., Hidalgo, C.A., Bustos, S., Coscia, M., Chung, S., Jimenez, J., Simoes, A., \& Yildirim, M.A. (2011). The atlas of economic complexity mapping paths to prosperity.

Hidalgo, C. A. (2009). The dynamics of economic complexity and the product space over a 42 year period. Center for International Development at Harvard University Working Paper 189. 
Hidalgo, C. A.,\& and Hausmann, R. (2009). The Building Blocks of Economic Complexity. PNAS, 106 (26): 10570-10575.

Lapatinas, A. (2016). Economic complexity and human development: A note. Economics Bulletin, 36(3): 1441-1452.

Pan, C.I., Chang, T., \& Wolde-Rufael, Y. (2015). Military spending and economic growth in the Middle East countries: Bootstrap panel causality test. Defence and Peace Economics, 26(24): 443-456.

Pesaran, M. H. (2004). General diagnostic tests for cross section dependence in panels. CWPE, 0435.

Pesaran, M. H. (2007). A simple panel unit root test in the presence of cross-section dependence. Journal of Applied Econometrics, 22: $265-312$.

Stojkoski, V., \& Kocarev, L. (2017). The relationship between growth and economic complexity: Evidence from Southeastern and Central Europe. MPRA, 77837.

Şak, N. (2015). Panel Eşbütünleşme Analizi. In Stata ile Panel Veri Modelleri. Ed.by Burak Güriş, İstanbul: Der Yayınları.

UN. (2019, March $\quad 3)$ Classification. Country https://www.un.org/en/development/desa/policy/wesp/wesp_current/2014wesp_country_classification.

UNDP. (1990). Human Development Report 1990, New York: Oxford University Press.

Yerdelen Tatoğlu, F. (2013). İleri Panel Veri Analizi Stata Uygulamalı. (2. b.). İstanbul: Beta. 